\title{
Communication-Contribution of Catalyst Layer Proton Transport Resistance to Voltage Loss in Polymer Electrolyte Water Electrolyzers
}

\author{
Journal Article \\ Author(s): \\ Babic, Ugljesa; Schmidt, Thomas J.; Gubler, Lorenz (D) \\ Publication date: \\ 2018-07-15 \\ Permanent link: \\ https://doi.org/10.3929/ethz-b-000283271
}

Rights / license:

Creative Commons Attribution 4.0 International

Originally published in:

Journal of the Electrochemical Society 165(15), https://doi.org/10.1149/2.0031815jes 


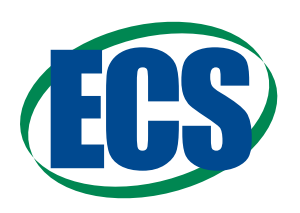

JES Focus Issue on Electrocatalysis - In Honor of Radoslav Adzic

\title{
Communication-Contribution of Catalyst Layer Proton Transport Resistance to Voltage Loss in Polymer Electrolyte Water Electrolyzers
}

\author{
Ugljesa Babic, $\circledast^{1, *}$ Thomas J. Schmidt, $\circledast^{1,2, * *}$ and Lorenz Gubler $\oplus^{1, * *, z}$ \\ ${ }^{I}$ Electrochemistry Laboratory, Paul Scherrer Institut, $\mathrm{CH}-5232$ Villigen PSI, Switzerland \\ ${ }^{2}$ Laboratory of Physical Chemistry, ETH Zürich, CH-8093 Zürich, Switzerland
}

\begin{abstract}
Mass transport losses $\left(\eta_{m t x}\right)$ play a significant role at high current densities in polymer electrolyte water electrolyzers (PEWEs). Previous work has shown that $\eta_{m t x}$ depends on the porous transport layer (PTL) structure, although a clear correlation between the material morphology and $\eta_{m t x}$ has not been established. In this work, we experimentally determine the overpotential $\eta_{C L a}^{H+}$ associated with the proton transport in the anodic catalyst layer by measuring the ionic resistance in the catalyst layer using electrochemical impedance spectroscopy (EIS) and the transmission-line model. We found that overpotentials, including $\eta_{C L a}^{H+}$, depend on the PTL morphologic surface properties.

(C) The Author(s) 2018. Published by ECS. This is an open access article distributed under the terms of the Creative Commons Attribution 4.0 License (CC BY, http://creativecommons.org/licenses/by/4.0/), which permits unrestricted reuse of the work in any medium, provided the original work is properly cited. [DOI: $10.1149 / 2.0031815 \mathrm{jes}$ ]

(cc) BY
\end{abstract}

Manuscript submitted March 15, 2018; revised manuscript received July 13, 2018. Published July 25, 2018. This paper is part of the JES Focus Issue on Electrocatalysis - In Honor of Radoslav Adzic.

It is necessary to identify voltage losses in PEWE on the cell level in order to optimize the design for higher efficiency. The ohmic overpotential is associated with the charge transport (ionic, electronic) in cell components and contact resistances. ${ }^{1-3}$ Kinetic losses $\left(\eta_{a c t}\right)$ are related to the electrochemical reactions, mainly the sluggish oxygen evolution reaction (OER). ${ }^{4}$ The mass-transport overpotential $\left(\eta_{m t x}\right)$ is still not well understood. Previous work has shown that $\eta_{m t x}$ occurs on the anode side, and was hypothesized to stem from the two-phase flow through the anodic PTL $\left(\mathrm{PTL}_{\mathrm{a}}\right){ }^{5}$ and the removal of $\mathrm{O}_{2}$ bubbles that hinder the water supply to the electrode. ${ }^{6}$ In this work we experimentally determine the overpotential $\eta_{C L a}^{H+}$ related to the proton transport resistance in the anode catalyst layer $\left(R_{C L a}^{H+}\right)$. This overpotential is often unaccounted for in PEWE and has so far been lumped together with general 'mass transport' losses.$^{5-7}$ Recently, Bernt and Gasteiger $^{12}$ calculated the effective proton transport resistance in the $\mathrm{CL}_{\mathrm{a}}$ from the electrode sheet resistance for proton conduction to be in a range from 6 to $171 \mathrm{~m} \Omega \mathrm{cm}^{2}$, depending on $\mathrm{CL}_{\mathrm{a}}$ ionomer content. The study presented here is the first to report experimentally determined $R_{C L a}^{H+}$ values and its dependence on the PTL $/ \mathrm{CL}_{\mathrm{a}}$ interface.

\section{Experimental}

Electrolysis cell and test-bench.-Experiments were performed using an in-house developed test-bench equipped with a SP-150 potentiostat and a HCP-803 80A booster from Biologic. Water was circulated at $400 \mathrm{~mL} \mathrm{~min}{ }^{-1}$ only in the anode cell compartment, while the electro-osmotically dragged water was discarded periodically from the cathodic gas-water separator. The PEWE cell with an active area of $25 \mathrm{~cm}^{2}$ was assembled using a Nafion 117 based E400 catalyst coated membrane (CCM) from Greenerity, with an Ir-based catalyst for the anode and the Pt-based catalyst for the cathode. Sintered-Ti PTLs T5, T10 and T20 from GKN were varied on the anode and cathode side. Data describing the cells with different PTLs will be designated with T5/T10/T20. The previous study from Suermann et al. ${ }^{5}$ included X-ray tomography characterization of dry samples, showing that the samples had similar porosity between $30-35 \%$. T5 and T10 have $d_{50}^{\text {particle }}$ of $68 \mu \mathrm{m}$, with T5 having smaller

\footnotetext{
*Electrochemical Society Student Member.

**Electrochemical Society Member.

${ }^{\mathrm{z}}$ E-mail: lorenz.gubler@psi.ch
}

pores, and the "smoothest" surface. The T20 sample had both the largest particles $\left(d_{50}^{\text {particle }}=128 \mu \mathrm{m}\right)$ and a higher fraction of larger pores. For details we refer to Ref. 3.

Operating conditions - electrolysis regime.-CCMs were conditioned for 12 hours prior to measurements by cycling the current density between 1 and $2 \mathrm{~A} \mathrm{~cm}^{-2}$ in 5 min intervals at $60^{\circ} \mathrm{C}$. The polarization curves were recorded galvanostatically at $60^{\circ} \mathrm{C}$, and the high frequency resistance (HFR) was measured at $10 \mathrm{kHz}$ for the $i R$-correction.

\footnotetext{
Operating conditions $-\mathrm{H}_{2} / \mathrm{N}_{2}$ regime.-For the determination of

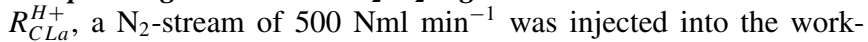
ing electrode (WE) water loop, while the reference/counter electrode (RE/CE) was supplied with humidified $\mathrm{H}_{2}$ at $400 \mathrm{Nml} \mathrm{min}^{-1}$. At the applied DC-bias of the cell, hydrogen evolution takes place at the $\mathrm{RE} / \mathrm{CE}$, and oxidation of hydrogen that has permeated through the membrane from the $\mathrm{H}_{2}$ to the $\mathrm{N}_{2}$ side at the WE. The DC current in this case is the limiting hydrogen crossover current. The PEWE cell was operated potentiostatically at $1.0,1.2$ and $1.4 \mathrm{~V}$, and the impedance was measured from $10 \mathrm{kHz}$ to $100 \mathrm{mHz}$. The measurements were performed in the potential region with higher capacitance to eliminate the effects of the inductive elements. ${ }^{8}$ No contribution of the faradaic current was observed at these potentials in the $\mathrm{H}_{2} / \mathrm{N}_{2}$ regime (cf. Supplementary Material, Figure S3). In this study, we analyze the WE AC response using a one-dimensional transmission-line model consisting of differential elements describing charge transfer and proton transport in the CL. The general model is widely used in fuel cell CL characterization ${ }^{8-10}$ and the governing equations are given in detail in the Supplementary Material. The proton transport losses in the $\mathrm{CL}_{\mathrm{a}}$ appear as $R_{C L a}^{H+} / 3$ in the polarization curve, under the assumption of uniform potential distribution in the CL. ${ }^{8-10}$ Due to a good agreement between the measured and the modeled impedance response (cf. Supplementary Material, Figure S2), we extrapolated the low frequency, capacitive response to the real axis obtaining the $R_{C L a}^{H+} / 3$ projections. This procedure was repeated for different PTLs to determine the impact of the CL/PTL interface on $R_{C L a}^{H+}$. The $R_{C L c}^{H+}$ contribution is assumed to be negligible as a result of the low charge transfer resistance of the hydrogen evolution reaction (HER). ${ }^{11}$ Furthermore, the fast HER takes place at the catalyst/membrane interface, resulting in a negligible effective $R_{C L c}^{H+}$
} 


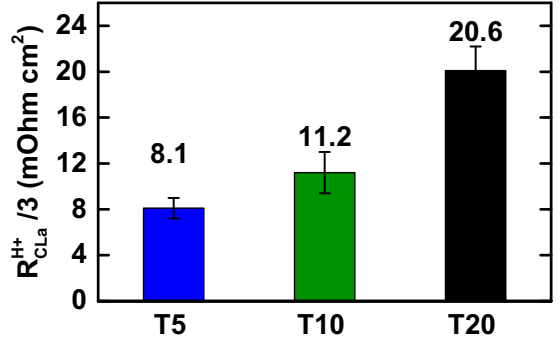

Figure 1. Proton transport resistance in the anode catalyst layer $\left(R_{C L a}^{H+}\right)$, extrapolated from the PEWE cell impedance in $\mathrm{H}_{2} / \mathrm{N}_{2}$ mode at $60^{\circ} \mathrm{C}$.

\section{Results and Discussion}

Proton transport resistance in the anode catalyst layer.-So far, there have not been any attempts to experimentally determine the $R_{C L a}^{H+}$ contribution to $\eta_{m t x}$. The values of $R_{C L a}^{H+} / 3$ are extrapolated from the impedance spectra from the $\mathrm{H}_{2} / \mathrm{N}_{2}$ operation (Figure 1) $\left(8.1 \pm 0.9 / 11.2 \pm 1.8 / 20.6 \pm 2.1 \mathrm{~m} \Omega \mathrm{cm}^{2}\right.$ for T5/T10/T20, respectively). The $R_{C L a}^{H+}$ appears to strongly depend on the interface between the PTL and the CL $\mathrm{L}_{\mathrm{a}}$, as the PTL with the coarsest and finest surfaces result in highest and lowest $R_{C L a}^{H+}$, respectively. To better comprehend the effect of the PTL/CL $L_{a}$ interface on the cell characteristics, we have conducted an overpotential analysis on the polarization curves.

Overpotential analysis.-The PEWE polarization curves were analyzed according to the Tafel model, with the procedure and equations given in detail in References 5-7. PEWE cell voltage is a sum of the thermodynamic, reversible cell voltage $E_{\text {rev }}(p, T)$, given by the Nernst equation, and the overpotentials, which can be broken down to kinetic $\eta_{\text {act }}$, ohmic $\eta_{\text {ohm }}$, and mass-transport $\eta_{m t x}$ contributions. ${ }^{7}$ Correcting the cell voltage, $E_{\text {cell }}$, using the HFR yields the $i R$-free cell voltage $\left(E_{I R-\text { free }}\right)$ and $\eta_{o h m}$. The Tafel slope was fitted in the low current density region $\left(0.01-0.08 \mathrm{~A} \mathrm{~cm}^{-2}\right)$ and subsequent subtraction of $E_{r e v}(p, T)$ yielded $\eta_{a c t}$. The difference between $E_{I R-\text { free }}$ and the extrapolated Tafel line yields residual losses, considered to be the results of mass transport losses. ${ }^{5-7}$

$$
E_{\text {cell }}=E_{\text {rev }}(p, T)+\eta_{\text {act }}+\eta_{\text {ohm }}+i \cdot R_{C L a}^{H+}+\eta_{\text {mtx-rest }}
$$

Polarization curves and the impedance spectra (Figure 2) reveal significant differences in cell performance with different PTLs. Although cells with T5 showed the lowest HFR, they are outperformed by the cells with T10 PTL. The cells with T20 exhibited both the highest HFR and different impedance response at low frequencies (Figure 2b), indicating higher mass transport losses. The difference in HFR most likely stems from a higher ohmic interfacial contact resistance in the cell when using coarser T20 compared to T5. Interestingly, Tafel slopes are somewhat different for the three cells;

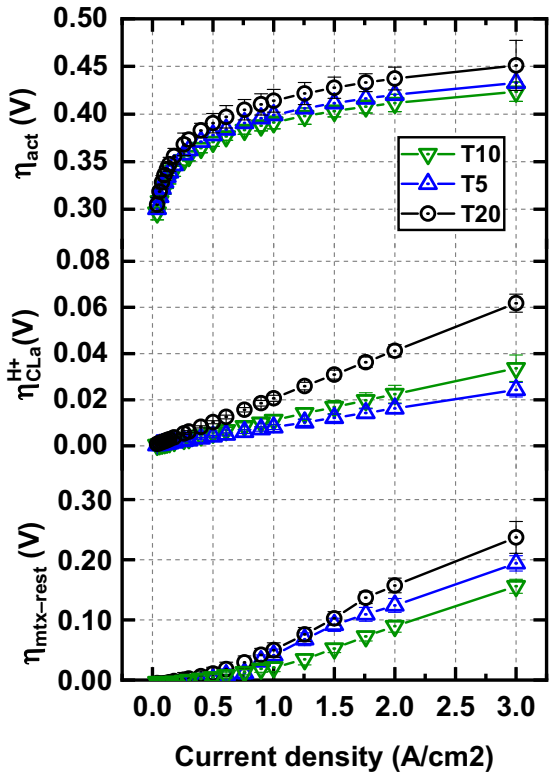

Figure 3. Activation $\left(\eta_{a c t}\right), C L_{a}$ proton transport $\left(\eta_{C L a}^{H+}\right)$ and the rest of the mass transport overpotential $\left(\eta_{m t x-\text { rest }}\right)$ for T5/T10/T20 cell configurations.

$71 \pm 1,68 \pm 1,78 \pm 2 \mathrm{mV} / \mathrm{dec}$ for T5, T10, T20, respectively. PTL-induced structural inhomogeneity in the $\mathrm{CL}_{\mathrm{a}}$ might result in the different apparent Tafel slopes. Overall, calculated overpotentials with different commercial PTLs are in line with the previous study from Suermann et al. ${ }^{5}$

Since $R_{C L a}^{H+} / 3$ appear as part of $\eta_{m t x}, \eta_{m t x}$ was corrected for the $R_{C L a}^{H+}$ contribution from the $\mathrm{H}_{2} / \mathrm{N}_{2}$ measurements to extract $\eta_{m t x-\text { rest }}$. $R_{C L a}^{H+}$ contributes 11,18 and $21 \%$ to $\eta_{m t x}$ at $3 \mathrm{~A} \mathrm{~cm}^{-2}$ for the cells with T5, T10 and T20 PTLs, respectively. The $\eta_{m t x-\text { rest }}$ still accounts for the major contribution to $\eta_{m t x}$ at high current densities and differs between the three configurations, being highest for T20 and lowest for T10 (Figure 3). A coarse PTL $\mathrm{a}_{\mathrm{a}}$ surface appears to be detrimental to the cell performance indicators. We offer the following tentative explanation: as the CCM deforms between the rigid Ti-PTLs, the $\mathrm{CL}_{\mathrm{a}}$ area under the solid PTL particles is compressed and its porosity is thereby reduced. The surface of T20 consists of larger particles, leading to more pronounced local reductions in porosity. We assume that proton transport takes place in the compacted $\mathrm{CL}_{\mathrm{a}}$ structure, as it is the area under the PTL particle in contact with the $\mathrm{CL}_{\mathrm{a}}$ that contributes to the OER. ${ }^{12,13}$ The water reaches the $\mathrm{CL}_{\mathrm{a}}$ through the voids on the PTL surface and relies on lateral diffusion through the ionomer binder to reach the active sites under the PTL solid particles (Figure 4). The T20 PTL surface consists of larger particles and pores, ${ }^{5}$ and would in turn result
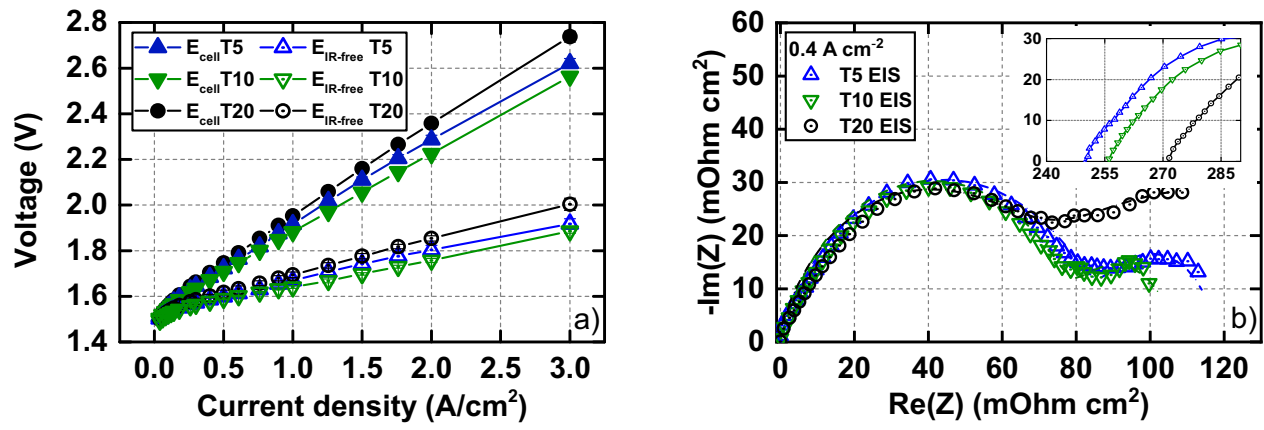

Figure 2. a) Polarization curves showing cell voltage $E_{\text {cell }}$ and the IR-free cell voltage $E_{I R-\text { free }}$ for T5/T10/T20 cell configurations at $60^{\circ} \mathrm{C}$. b) iR-free impedance response (subtracted high frequency intercept) $(10 \mathrm{kHz} \rightarrow 0.1 \mathrm{~Hz})$ for three cell configurations measured at $0.4 \mathrm{~A} \mathrm{~cm}^{-2}$, with the inset showing the uncompensated HFR intercept. 


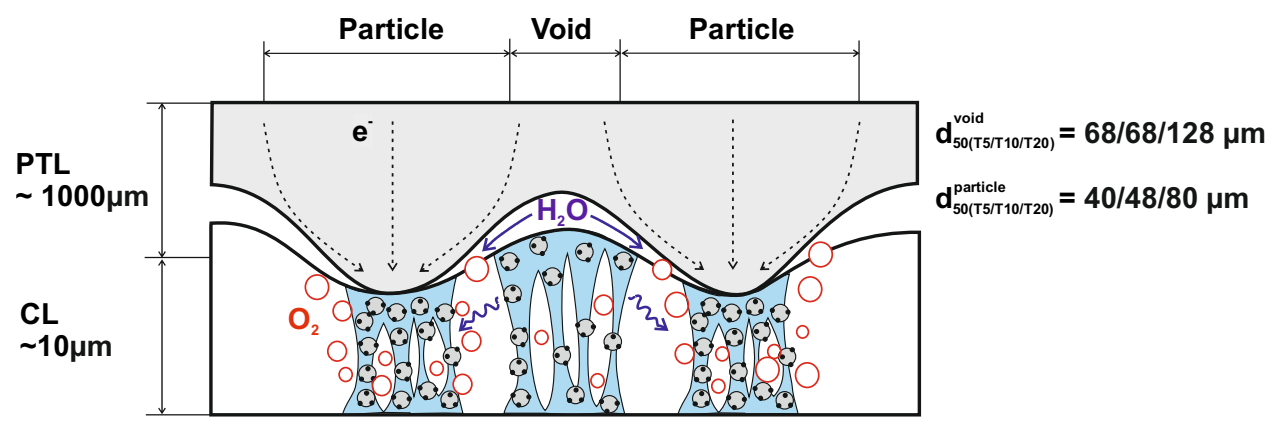

Figure 4. Schematic of the $\mathrm{CL}_{\mathrm{a}} / \mathrm{PTL}_{\mathrm{a}}$ interface. Macroporous sintered-Ti PTLs are thought to result in local porosity variations in the $\mathrm{CL}_{\mathrm{a}}$, causing increased $R_{C L a}^{H+}$. Water needs to diffuse laterally through the ionomer to reach active sites under the Ti-particles. PTL pore and particle size are obtained from Reference 5.

in larger diffusion distances for the water in the $\mathrm{CL}_{\mathrm{a}}$ ionomer, and thus higher $\eta_{m t x-\text { rest }}$. The different $\eta_{m t x-\text { rest }}$ for the T5 and T10 might stem from the more constrained T5 structure, with a higher fraction of small, potentially bottlenecking pores. ${ }^{5}$ The compaction of the $\mathrm{CL}_{\mathrm{a}}$ under the PTL particle leads to higher degree of ionomer binder confinement and inhomogeneous wetting of the $\mathrm{CL}_{\mathrm{a}}$ active sites, resulting in increased $R_{C L a}^{H+}{ }^{14,15} \mathrm{SEM}$ images of the $\mathrm{CL}_{\mathrm{a}}$ surface and CCM cross-sections are presented in the Supplementary Material to give more insight into the impact of the interface morphology on the CCM physical properties.

\section{Conclusions}

We have analyzed the impact of the PTL properties on the cell characteristics in a PEWE cell by conducting a detailed overpotential analysis. Experimentally determined $R_{C L a}^{H+}$ vary based on the PTL surface morphology, with the highest and lowest values measured in the case of cells with coarsest and finest PTL surfaces, respectively. The variations in $R_{C L a}^{H+}$ are most likely caused by confinement effects in the $\mathrm{CL}_{\mathrm{a}}$, resulting in inhomogeneous water distribution along the $\mathrm{CL}_{\mathrm{a}}$. Overall the $R_{C L a}^{H+}$ accounts for 11,18 and $21 \%$ of $\eta_{m t x}$ at $3 \mathrm{~A} \mathrm{~cm}^{-2}$ for the cells with T5, T10, and T20 sinters, respectively. The residual mass transport loss, $\eta_{m t x-\text { rest }}$, varies between the cells with different PTLs, and is assumed to be influenced the PTL/CL interface. The coarse PTL/CL $\mathrm{L}_{\mathrm{a}}$ interface results in longer water diffusion paths in the $\mathrm{CL}_{\mathrm{a}}$.

\section{Acknowledgment}

Funding by the Swiss Federal Office of Energy (grant-no. 501198$01)$ is gratefully acknowledged.

\section{ORCID}

Ugljesa Babic (1D https://orcid.org/0000-0002-6774-1001

Thomas J. Schmidt (D) https://orcid.org/0000-0002-1636-367X

Lorenz Gubler (D) https://orcid.org/0000-0002-8338-6994

\section{References}

1. M. Carmo, D. L. Fritz, J. Mergel, and D. Stolten, International Journal of Hydrogen Energy, 38, 4901 (2013).

2. U. Babic, M. Suermann, F. N. Büchi, L. Gubler, and T. J. Schmidt, Journal of The Electrochemical Society, 164, F387 (2017)

3. P. Lettenmeier, R. Wang, R. Abouatallah, B. Saruhan, O. Freitag, P. Gazdzicki, T. Morawietz, R. Hiesgen, A. S. Gago, and K. A. Friedrich, Scientific Reports, 7 , 44035 (2017).

4. E. Fabbri, A. Habereder, K. Waltar, R. Kötz, and T. J. Schmidt, Catal. Sci. Technol., 4, 3800 (2014).

5. M. Suermann, K. Takanohashi, A. Lamibrac, T. J. Schmidt, and F. N. Büchi, Journal of The Electrochemical Society, 164, F973 (2017).

6. H. Ito, T. Maeda, A. Nakano, A. Kato, and T. Yoshida, Electrochimica Acta, 100, 242 (2013).

7. M. Suermann, T. J. Schmidt, and F. N. Büchi, Electrochimica Acta, 211, 989 (2016).

8. Y. Liu, M. W. Murphy, D. R. Baker, W. Gu, C. Ji, J. Jorne, and H. A. Gasteiger, Journal of The Electrochemical Society, 156, B970 (2009).

9. R. Makharia, M. F. Mathias, and D. R. Baker, Journal of The Electrochemical Society, 152, A970 (2005)

10. S. S. Kocha, in Handbook of Fuel Cells, Fundamentals, Technology, and Applications, Vol. 3, W. Vielstich, H. Gasteiger, and A. Lamm, John Wiley \& Sons, Ltd. New York (2010).

11. M. Bernt and H. A. Gasteiger, Journal of The Electrochemical Society, 163, F3179 (2016).

12. Z. Kang, J. Mo, G. Yang, S. T. Retterer, D. A. Cullen, T. J. Toops, J. B. Green Jr, M. M. Mench, and F.-Y. Zhang, Energy Environ. Sci., 10, 166 (2017).

13. J. Mo, Z. Kang, S. T. Retterer, D. A. Cullen, T. J. Toops, J. B. Green, M. M. Mench, and F.-Y. Zhang, Science Advances, 2 (2016).

14. A. Kusoglu and A. Z. Weber, Chem Rev, 117, 987 (2017).

15. D. Cericola and M. E. Spahr, Electrochimica Acta, 191, 558 (2016). 